\section{AUTORES}

M. ${ }^{a}$ Camino Barcenilla Tirapu José Miguel Gamboa Baztán Roldán Jimeno Aranguren

José Vicente Urabayen Azpilikueta

\section{ADSCRIPCIÓN PROFESIONAL}

Grupo de trabajo de la Ley Foral de Derechos Culturales de Navarra.

\section{TíTULO}

La Ley Foral de Derechos Culturales de Navarra: una norma pionera en Europa.

\section{CORREO-E}

mc.barcenilla.tirapu@navarra.es

jm.gamboa.baztan@navarra.es

roldan.jimeno@unavarra.es

tecnicocultura@villava.es

\section{RESUMEN}

La Comunidad Foral de Navarra aprobó recientemente la Ley Foral 1/2019, de 15 de enero, de Derechos Culturales de Navarra, una norma pionera e innovadora en Europa. Con la implementación de un marco de reflexión conjunto entre las políticas culturales y los derechos culturales se les otorga pleno reconocimiento como derechos de carácter fundamental, indispensables para el desarrollo integral del ser humano, promoviendo así una ciudadanía cultural que ejercite su derecho a la cultura, la participación en la misma así como los procesos culturales y creativos.

\section{PALABRAS CLAVE}

Derechos culturales, innovación, políticas culturales, participación, acceso, vida cultural.

\section{AUTHORS}

M. ${ }^{\text {a }}$ Camino Barcenilla Tirapu José Miguel Gamboa Baztán Roldán Jimeno Aranguren José Vicente Urabayen Azpilikueta

\section{PROFESSIONAL AFFILIATION}

Workgroup of the Foral Law of Cultural Rights of Navarra.

\section{TITLE}

The Foral Law of Cultural Rights of Navarre: a pioneering norm in Europe.

\section{E-MAIL}

mc.barcenilla.tirapu@navarra.es

jm.gamboa.baztan@navarra.es

roldan.jimeno@unavarra.es

tecnicocultura@villava.es

\section{ABSTRACT}

The Foral Community of Navarre recently passed the Foral Law 1/2019, of 15 January, on Cultural Rights of Navarre, a pioneering and innovative law in Europe. With the implementation of a joint reflection framework between cultural policies and cultural rights, cultural rights are granted full recognition as fundamental rights and indispensable for the integral development of the human being, by promoting a cultural citizenship that exercises its right to culture, to participation in it as well as in cultural and creative processes.

\section{KEYWORDS}

Cultural rights, innovation, cultural policies, participation, access, cultural life.

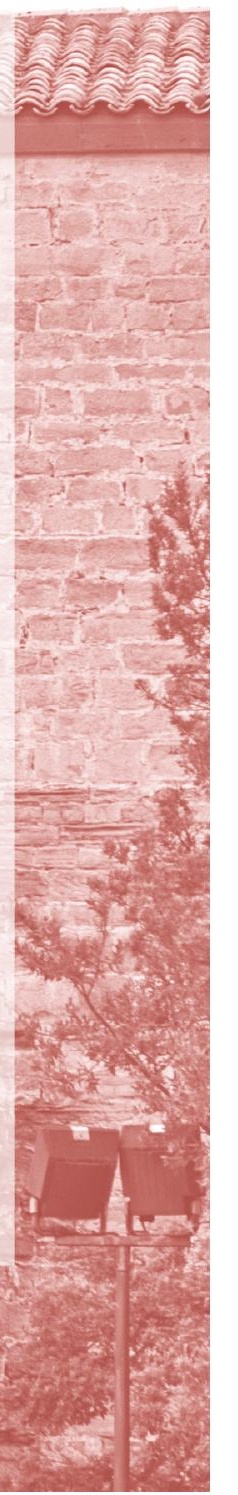




\title{
La Ley Foral de Derechos Culturales de Navarra: una norma pionera en Europa
}

\author{
M. a Camino Barcenilla Tirapu \\ José Miguel Gamboa Baztán \\ Roldán Jimeno Aranguren \\ José Vicente Urabayen Azpilikueta
}

\section{Introducción}

La Ley Foral 1/2019, de 15 de enero, de Derechos Culturales de Navarra, conforme a su disposición final quinta, entró en vigor el 26 de enero de 2019, salvo los apartados 2, 3, 4, 5 y 6 del artículo 10 "Bienes del Patrimonio Cultural de Navarra", que tendrán vigor al año de la publicación de la Ley Foral en el Boletín Oficial de Navarra.

Se trata de una norma pionera e innovadora en Europa, que pone el foco en la ciudadanía y sus derechos en relación con la cultura y las artes como un derecho humano más. La Ley tiene como objetivo principal, asegurar y promocionar los derechos culturales y su pleno reconocimiento como derechos de carácter fundamental. Este objetivo, no solo implica el derecho de los ciudadanos en su conjunto, sino que lo reconoce también ante el conjunto de artistas, creadores, gestores, promotores y profesionales. Además de ello, insta a las administraciones públicas competentes en la materia a promover políticas culturales novedosas que establezcan el valor de la cultura como bien común y sus derechos de acceso y participación como pilares necesarios para alcanzar una sociedad más igualitaria y democrática.

\section{Antecedentes inspiradores de la Ley Foral de} Derechos culturales de Navarra

La Ley navarra surge de un profundo análisis de las conferencias mundiales sobre cultura, así como de la diferente normativa europea y americana relativa a los derechos culturales. En este sentido, se partió de la realidad de que los derechos culturales están escasamente desarrollados en comparación con otros derechos humanos. La insuficiente atención que se les ha prestado por la doctrina ha conllevado su consideración como derechos de prioridad menor, a pesar de tratarse de un derecho universal. Januzs Symonides ha reflejado esta realidad cuando denunció que constituían una de categoría subdesarrollada de los derechos humanos:

Los derechos culturales suelen calificarse de "categoría subdesarrollada" de derechos humanos. Esta denominación se escogió como título del seminario celebrado en 1991 en la Universidad de Friburgo y fue ampliamente aceptada entonces. Sugiere que, en comparación con otras categorías de derechos humanos civiles, políticos, económicos y sociales los derechos culturales son los menos desarrollados por lo que atañe a su alcance, contenido jurídico y posibilidad 
de hacerlos respetar. En realidad, necesitan más elucidación, clasificación y fortalecimiento. La palabra "desarrollo" sugiere, en cambio, el proceso de creación de nuevos derechos, punto de vista que puede ser cuestionado, ya que la lista existente de derechos culturales es relativamente exhaustiva. Así pues, el problema se vincula más bien a la circunstancia de que estos derechos son descuidados o subestimados y tratados como "parientes pobres" de otros derechos humanos ${ }^{1}$.

El antecedente más remoto de los derechos culturales son la Declaración de los Derechos de Virginia (1776) - dignidad - y la Declaración sobre los derechos de la Asamblea Francesa del hombre y del ciudadano (1789). Ambas declaraciones, formuladas desde la separación de poderes y la soberanía popular, señalan el derecho al gozo de la vida o derecho a la felicidad.

Ya en el siglo XX, la Declaración Universal de los Derechos Humanos de Naciones Unidas de 1948, y a su conocido artículo 27, que establece que:

Toda persona tiene derecho a tomar parte libremente en la vida cultural de la comunidad, a gozar de las artes y a participar en el progreso científico y en los beneficios que de él resulten.

Toda persona tiene derecho a la protección de los intereses morales y materiales que le correspondan por razón de las producciones científicas, literarias o artísticas de que sea autora.

La Declaración también regula los deberes de los ciudadanos hacia la comunidad en su artículo 29, cuando señala que «Toda persona tiene deberes respecto a la comunidad, puesto que solo en ella puede desarrollar libre y plenamente su personalidad». Este texto también reconoce otros derechos relativos a la vida cultural, como la libertad de pensamiento, de conciencia y de religión (artículo 18), la libertad de opinión y de expresión (artículo 19), el derecho a la libertad de reunión y de asociación (artículo 20), el derecho al descanso y al tiempo libre (artículo 24) y el derecho a la educación (artículo 26), entre otros.

A partir de la Declaración de los Derechos Humanos, las constituciones de los diferentes Estados fueron reconociendo los derechos culturales, de esta manera surge la obligación de los gobiernos, de proporcionar condiciones para su desarrollo y para el florecimiento de los mismos. Los derechos culturales son parte de los derechos humanos, son universales, indivisibles e interdependientes. Esto queda recogido en el artículo 27.1 de la Carta Internacional de los Derechos Humanos, en este artículo se recoge que toda persona tiene derecho a formar parte libremente en la vida cultural. Por su parte, el Tratado de Roma de 25 de marzo de 1957, que dio origen a la Comunidad Económica Europea, en su artículo 36 referente a la libre circulación de mercancías, aludía a los bienes del patrimonio histórico-artístico. Sin embargo, hubo que esperar a la Conferencia Mundial de la UNESCO de 1966 - sin carácter vinculante - que aprobó la Declaración sobre los Principios de la Cooperación Cultural Internacional, para asistir a una primera reivindicación de que toda cultura tiene una dignidad y un valor que deben ser respetados. Por vez primera se reivindicó el valor de la cultura como elemento de cohesión y desarrollo, de ahí que los poderes públicos estaban obligados a protegerla.

Avanzando en el tiempo, en la declaración solemne sobre la Unión Europea de Stuttgart (1983), los jefes de estado o de gobierno de los entonces miembros de las Comunidades Europeas se pronunciaron a favor de la cooperación cultural y de promover actividades comunes en los ámbitos de difusión cultural. Pero no fue hasta 1992, con el Tratado de la Unión Europea - más conocido como Tratado de Maastricht_-, cuando, por primera vez, la Unión Europea adquirió formalmente competencias en materia cultura.

Con el artículo 128 - 151, tras la nueva numeración introducida por el Tratado de Ámsterdam—-, se atribuyó a la Comunidad Europea una cierta - aunque no muy ampliacompetencia en materia cultural y con ello la posibilidad de desarrollar acciones en el ámbito de la cultura. En el referido artículo del Tratado de Maastricht se indicó que desde las instituciones comunitarias se debían fomentar las culturas de los Estados miembros, teniendo en cuenta la diversidad nacional y regional, y también poner de relieve el patrimonio cultural común, con lo que se daba carta de naturaleza a dos realidades culturales: un denominador común y toda la diversidad presente en los Estados miembros. El principio inspirador sobre el derecho a la diversidad cultural está presente en este y en otros textos europeos, incluso en los programas que desarrolla para los sectores culturales y creativos.

Llegados al siglo XXI, son diversos los textos y documentos internacionales los que aluden al derecho de toda persona a participar en la vida cultural, destacando la Declaración Universal sobre la Diversidad Cultural, la Observación General n 21 al art. 15.1, a) del Pacto Internacional, los informes periódicos y sectoriales de la Relatora Especial 
en la esfera de los derechos culturales o, la Convención de la UNESCO sobre la protección y la promoción de la diversidad cultural. Sobresalen, entre todos, dos textos fundamentales que citan de forma manifiesta los derechos culturales, ambos de la UNESCO: la Declaración Universal de la sobre la Diversidad Cultural de 2001 y la Declaración de Friburgo de 2007. Sabido es que la Declaración Universal de la UNESCO considera la diversidad cultural un patrimonio común de la humanidad, cuando en su primer artículo se establece que:

La cultura adquiere formas diversas a través del tiempo y del espacio. Esta diversidad se manifiesta en la originalidad y la pluralidad de las identidades que caracterizan los grupos y las sociedades que componen la humanidad. Fuente de intercambios, de innovación y de creatividad, la diversidad cultural es, para el género humano, tan necesaria como la biodiversidad para los organismos vivos. En este sentido, constituye el patrimonio común de la humanidad y debe ser reconocida y consolidada en beneficio de las generaciones presentes y futuras.

La Declaración señala en los artículos 4, 5 y 6 la relación entre la Diversidad Cultural y los Derechos Humanos. En concreto, el artículo 4 indica que «la defensa de la diversidad cultural es un imperativo ético, inseparable del respeto de la dignidad de la persona humana», a lo que añade el quinto que «los derechos culturales son parte integrante de los derechos humanos, que son universales, indisociables e interdependientes». Por su parte, el artículo 6 avanza hacia una diversidad cultural accesible a todos, preceptuando que

la libertad de expresión, el pluralismo de los medios de comunicación, el plurilingüismo, la igualdad de acceso a las expresiones artísticas, al saber científico y tecnológico - comprendida su presentación en forma electrónica - y la posibilidad, para todas las culturas, de estar presentes en los medios de expresión y de difusión, son las garantes de la diversidad cultural.

A su vez, el artículo 7 reconoce la importancia del patrimonio cultural:

Toda creación tiene sus orígenes en las tradiciones culturales, pero se desarrolla plenamente en contacto con otras culturas. Ésta [sic] es la razón por la cual el patrimonio, en todas sus formas, debe ser preservado, realzado y transmitido a las generaciones futuras como testimonio de la experiencia y de las aspiraciones humanas, a fin nutrir la creatividad en toda su diversidad e instaurar un verdadero diálogo entre las culturas.

La Declaración de Friburgo es un texto profundamente renovado, gestado a partir de un proyecto redactado para la UNESCO por un grupo internacional de académicos, el grupo de Friburgo, constituido en 1995. Esta Declaración se dirige a los actores de los tres sectores — público (los Estados y sus instituciones), civil (las organizaciones no gubernamentales y otras asociaciones e instituciones sin ánimo de lucro) y privado (las empresas) — , para favorecer su reconocimiento y puesta en práctica, en los niveles locales, nacionales, regionales y universales.

La Declaración reúne y hace explícitos derechos que ya están reconocidos en numerosos instrumentos, aunque de manera dispersa. La clarificación es necesaria para demostrar la importancia crucial de los derechos culturales, como también la de las dimensiones culturales de los demás derechos humanos.

Descendiendo al marco normativo estatal, la Constitución establece que todos los españoles tienen derecho de acceso a la cultura. La labor de promover y tutelar este derecho aparece regulada en el art. 44, apartado 1 de la Constitución Española, cuando recoge que corresponde a los poderes públicos, con las obligaciones que esto conlleva, respetar, proteger y facilitar, y promover, su ejercicio efectivo. A pesar de estar reconocido este derecho en el ordenamiento jurídico español, su contenido no se concreta, y actualmente por esta razón, hay una necesidad clara de que el legislador lo desarrolle. Esta facultad puede ser ejercida sin perjuicio de que los jueces y tribunales, en el ejercicio de su función jurisdiccional, introduzcan precisiones o establezcan interpretaciones.

A pesar de esa falta de concreción, tanto en el ordenamiento estatal como foral existe normativa sectorial que contribuye a perfilar ese derecho en relación con determinados ámbitos de la cultura. Asimismo, los nuevos estatutos de autonomía promulgados a mediados de los dos mil fueron incorporando los derechos culturales en su articulado. Pero se hacía necesaria una ordenación jurídica general, clara y precisa de los derechos culturales en leyes autonómicas, sustentadas sobre los valores principales de estos: universalidad y reconocimiento de la diversidad cultural y libertad de elegir 
la propia identidad cultural y decidir la participación o no en la vida cultural y de qué modo, pero siempre en absoluto respeto hacia los derechos humanos y la dignidad de las personas.

\section{Las políticas culturales y los derechos cultura- les: un binomio necesario}

Habida cuenta del marco normativo internacional, europeo y español, en Navarra, el Parlamento de Navarra entendió la necesidad de concretar los derechos culturales y para ello promovió, a través del Gobierno de Navarra, la elaboración del Anteproyecto de Ley de derechos culturales, con el horizonte de cambiar el criterio que alberga el concepto «derecho a la cultura» por el de «derechos culturales».

Las políticas y los derechos culturales siempre han estado entrelazados - a veces no de manera consciente- en el marco de los deberes y las obligaciones que las administraciones públicas consideraban tener hacia la ciudadanía en el uso de los elementos y oportunidades que genera la cultura, en su sentido más amplio.

Actualmente, la Unión Europea reconoce en la Estrategia 2020 el papel central de la cultura - en la denominación de industria cultural y creativa - y su desempeño para el crecimiento, la innovación, la competitividad y el futuro de la Europa comunitaria y de su ciudadanía, generando territorios creativos. En otros lugares del mundo, sin embargo, siguen poniendo el acento en conservar los elementos del patrimonio cultural en casos de conflicto armado, en la cultura popular y sus tradiciones como acervo común, en la permanencia de las lenguas como idiosincrasia de una comunidad, en los pecios y sus derechos como patrimonio subacuático del fondo del mar, o en los derechos de autoría y propiedad intelectual, entre otros.

En las diferentes conferencias mundiales de la cultura del siglo XX (México, Venecia, Estocolmo) organizadas por la UNESCO, ya se plasmaban las tareas esenciales de las políticas culturales, entre ellas la responsabilidad de las administraciones para velar por la vida cultural de la ciudadanía a través de la financiación y de la planificación de la cultura. De alguna manera, se estaba señalando el camino del binomio política-derecho cultural, considerándose que el ámbito público tenía que estar presente en su desarrollo al tratarse de un derecho de la ciudadanía.

La Conferencia Intergubernamental sobre los Aspectos Institucionales, Administrativos y Financieros de las Políticas Culturales, más conocida como la Conferencia de
Venecia (1970), fue la primera reunión de políticas culturales donde se resaltó que todos los seres humanos tienen derecho a participar en el patrimonio y en la actividad cultural de la comunidad, además de subrayar el papel que debía desempeñar los Estados en torno a los derechos culturales.

En la Conferencia de Estocolmo (1998) se repitieron estos objetivos, aunque con una formulación más abstracta, relacionándola en todo caso con los derechos culturales, incidiendo en la cración de un medio humano favorable. En la Conferencia Munidal sobre las Políticas Culturales de México (1982) se había reconocido que la cultura tenía escaso apoyo financiero en la mayoría de los Estados, a los que se recomendó el establecimiento de un porcentaje adecuado para la cultura. En Estocolmo también se insistió en la necesidad de incrementar las inversiones para el desarrollo cultural. Participando de estos mismos planteamientos, la Ley Foral 1/2019, de 15 de enero, de Derechos Culturales de Navarra, destaca la importancia de una financiación adecuada para crear el medio cultural favorable que permita su desarrollo.

Así pues, las declaraciones, convenciones y conferencias del siglo XX ponen en relación la gestión, planificación y financiación (políticas culturales) para un desarrollo humano cultural favorable que permita participar en la vida cultural y gozar de las artes. Faltaba, sin embargo, pasar de las declaraciones a textos legislativos concretos. La Comunidad Foral de Navarra ha sido pionera en un contexto de política cultural, promulgando la Ley Foral 1/2015, de Derechos culturales de Navarra.

\section{La aprobación de una norma pionera en Euro- pa: la Ley Foral de derechos culturales de Navarra}

Los derechos culturales - con relación a las políticas culturales - pueden interpretarse en varios sentidos. Para algunos constituyen un principio de democratización cultural (acceso a la cultura), para otros son el reconocimiento de la multiculturalidad «pluralismo cultural» y en todo caso suponen el reconocimiento de las prácticas expresivas y culturales de la ciudadanía (democracia cultural), y son un instrumento esencial que garantiza los derechos culturales como derechos humanos.

La reciente Ley Foral 1/2019, de 15 de enero, de Derechos Culturales de Navarra, tiene un carácter innovador, dada la inexistencia de una norma de estas características en contextos europeos y estatales. Cuando en Europa se habla de la Estrategia 2020 en la generación de territorios creati- 
vos para el crecimiento, la innovación, la competitividad y el futuro de la Europa comunitaria, Navarra se posiciona en este sentido con una norma - construida con un proceso de participación - que vela por los diferentes derechos culturales de la ciudadanía y que persigue los siguientes objetivos:

1. Implementar un marco de reflexión conjunto entre las políticas culturales y los derechos culturales, estableciendo el marco referencial para las leyes sectoriales en la materia.

2. Pleno reconocimiento de los derechos culturales como derechos de carácter fundamental, integrantes de los derechos humanos que son universales, indivisibles e interdependientes.

3. Establecer las condiciones para la igualdad en el acceso a la cultura, orientadas por la pretensión de equilibrio y compensación social, sectorial y territorial.

4. Constatar el valor de los derechos culturales como base indispensable para el desarrollo integral del ser humano.

5. Promover y proteger la diversidad cultural y lingüística de Navarra, su pluralidad de identidades, su notable historia, su patrimonio material e inmaterial, sus variadas tradiciones que la conforman y enriquecen, así como su permanente creatividad que se manifiesta en nuevos lenguajes e interpretaciones, que ponen de manifiesto una cultura en proceso dinámico y vivo.

\section{La Ley Foral pretende}

\section{poner en valor las políticas}

\section{culturales y establecer}

obligaciones de las

\section{administraciones públicas}

\section{en relación con los derechos}

6. Establecer el correspondiente marco institucional que garantice la transparencia y la corresponsabilidad en la gestión pública de la cultura y facilite la participación ciudadana y del sector en la concepción de las políticas culturales y en la evaluación del impacto de dichas políticas en el desarrollo de Navarra.

7. Promover una ciudadanía cultural que ejercite su derecho a la cultura y a la participación en la vida cultural y en los procesos culturales y creativos.

8. Garantizar una financiación pública adecuada de la cultura, acorde con la media de las regiones europeas que se asemejan a Navarra.

Con esos objetivos se inició un proceso de creación - y redacción - con vocación participativa, abierto al conjunto de la ciudadanía con la idea de crear una norma común y compartida por los sectores culturales y creativos de la Comunidad Foral de Navarra.

La Ley Foral pretende poner en valor las políticas culturales y establecer obligaciones de las administraciones públicas en relación con los derechos culturales. Se ha promulgado con la finalidad de asegurar y promocionar los derechos culturales y su pleno reconocimiento como derechos de carácter fundamental. Este objetivo no solo implica el derecho de los ciudadanos en su conjunto, sino que lo reconoce también ante el conjunto de artistas, creadores, gestores, promotores y profesionales de la cultura. Insta a las administraciones públicas competentes en la materia a promover políticas culturales novedosas que establezcan el valor de la cultura como bien común y sus derechos de acceso y participación como pilares necesarios para alcanzar una sociedad más igualitaria y democrática.

La Ley Foral tiene su origen en el Acuerdo Programático para el Gobierno de Navarra (Legislatura 2015-2019), que establece que la política cultural debe responder a una doble finalidad:

Por una parte, promover valores, formas de vivir y pensar que cohesionen la sociedad y conformen marcos de convivencia basados en la pluralidad, libertad, creatividad, justicia social, inclusión, participación y democracia. Y, por otra, desplegar al máximo la dimensión creativa e innovadora de la cultura para responder a los retos que afrontan las sociedades contemporáneas. El nuevo reto de la política cultural es materializar el desarrollo comunitario centrado en la proximidad y la participación. 
Entre los principios que debían regir las políticas culturales de la legislatura establecidos en el mencionado acuerdo se identifican los derechos culturales como derechos fundamentales del ser humano, así como el compromiso del diseño y elaboración de una Ley Foral de Derechos Culturales.

Se consideró, por tanto, que la aprobación de una Ley Foral de Derechos Culturales de Navarra era necesaria para la puesta en valor de los derechos culturales, tanto para la ciudadanía en su conjunto como para los artistas, creadores, gestores, promotores y profesionales, y las administraciones públicas competentes en la materia, generando contextos de políticas culturales novedosos y avanzados en el siglo XXI.

De ese modo se avanzaba en una normativa común, superando la fragmentada o específica de los sectores culturales propia de las dos últimas décadas, en la que los principios rectores de las políticas culturales y las garantías relacionadas con el acceso a la cultura incurrían en ocasiones en desajustes y visiones fragmentadas.

Se debe indicar también que la Ley Foral de Derechos Culturales de Navarra también respondió a la demanda que el sector profesional de la cultura venía manifestando en los últimos años y que se expresó corporativamente en la II Conferencia Estatal de la Cultura celebrada en marzo de 2015 en Pamplona, en el palacio de congresos Baluarte, promovida por la Federación Estatal de Asociaciones de Gestores Culturales y la Asociación de Profesionales de la Gestión Cultural de Navarra. Se presentó aquí el Pacto por la Cultura, cuya recomendación $23 .^{\circ}$ instó a los gobiernos de las comunidades autónomas a la aprobación y desarrollo de leyes de derechos culturales, con el objeto de

establecer los contenidos del derecho a la cultura y de participación en la vida cultural de la comunidad, sentando unas condiciones y garantías básicas comunes y afirmando el significado de los derechos culturales como derechos humanos para todos los ámbitos y sectores culturales (patrimonio cultural, propiedad intelectual, industrias culturales...), así como la condición intrínseca de dichos derechos para la dignidad humana y para el desenvolvimiento de la ciudadanía democrática.

En enero de 2017, a solicitud del Departamento competente en materia de cultura del Gobierno de Navarra, se constituyó un grupo de trabajo para la elaboración del texto del anteproyecto de ley foral, encargado de realizar el análisis de fuentes doctrinales, legislativas y jurisprudenciales sobre la materia y redactar el texto que incluiría, además, las aporta- ciones recibidas de los procesos participativos que se abrirían en adelante. Este grupo estuvo constituido por M. ${ }^{\text {a }}$ Camino Barcenilla Tirapu, jefa de la Sección de Recursos y Desarrollo Estratégico de la Dirección General de Cultura-Institución Príncipe de Viana, José Miguel Gamboa Baztán, secretario general técnico del Departamento de Cultura, Deporte y Juventud, y por los vocales del Consejo Navarro de Cultura José Vicente Urabayen Azpilikueta y Roldán Jimeno Aranguren, que ejerció de coordinador. Este equipo redactor mantuvo catorce reuniones de trabajo entre enero de 2017 y octubre de 2018. Se contó, asimismo, con el asesoramiento de Javier Barcelona Llop, catedrático de Derecho Administrativo de la Universidad de Cantabria y experto en derechos culturales.

Siguiendo el procedimiento establecido en la elaboración de anteproyectos de leyes forales por parte del Gobierno de Navarra, se realizó una consulta pública previa a la elaboración del Anteproyecto de Ley Foral de Derechos Culturales, en el Portal de Gobierno Abierto de Navarra. Esta consulta previa fue sometida a la participación ciudadana desde el 4 hasta el 24 de octubre de 2017. En el plazo concedido al efecto, se presentaron dos aportaciones suscritas por la Asociación de Archiveros de Navarra y la Asociación de Profesionales de la Gestión Cultural de Navarra. El informe correspondiente fue publicado en el citado Portal.

Una vez elaborado el Anteproyecto de Ley Foral de Derechos Culturales de Navarra, se sometió el texto a exposición pública en dicho Portal desde el 26 de febrero hasta el 23 de marzo de 2018. Presentaron alegaciones las siguientes personas y entidades: Asociación de Profesionales de la Gestión Cultural de Navarra (apgcna), Comité de Entidades Representantes de Personas con Discapacidad de Navarra (cermin), Filmoteca de Navarra (Alberto Cañada), Fundación atena, Universidad de Navarra, Jesús Vélaz, Juana M. ${ }^{a}$ Marco Goñi y Martín Gamboa. El informe de valoración de las aportaciones y sugerencias formuladas se publicó en el Portal de Gobierno Abierto de Navarra y se notificó a las personas y entidades que habían presentado alegaciones.

Por parte del Departamento de Cultura, Deporte y Juventud también se llevaron a cabo, de manera complementaria, otros instrumentos de participación. La primera exposición pública del borrador de la Ley Foral se realizó en la Jornada "Construyendo el Plan Estratégico de Cultura, 2017-2023: Iniciativas para el desarrollo de la política cultural", organizada por la Dirección General de Cultura-Institución Príncipe de Viana del Gobierno de Navarra y celebrada en el Centro de Arte Contemporáneo de Huarte el 31 de octubre de 2017. Intervinieron en la misma el catedrático de Derecho Administra- 
tivo Jesús Prieto disertando sobre «los derechos culturales en un marco global», y Roldán Jimeno, que presentó las líneas generales del Anteproyecto de Ley Foral de Derechos Culturales. Asistieron a la Jornada sesenta personas, con una nutrida presencia de entidades y organizaciones, públicas y privadas, del sector cultural, así como representantes del Parlamento de Navarra.

Por esas fechas y en los meses siguientes, se realizaron reuniones y consultas con las siguientes personas, organismos y entidades: Consejo Navarro de Cultura; Departamentos de Desarrollo Económico, de Desarrollo Rural, Medio Ambiente y Administración Local y de Hacienda y Política Financiera del Gobierno de Navarra; la Federación Navarra de Municipios y Concejos; miembros de la Comisión de Cultura del Parlamento de Navarra de los diferentes grupos parlamentarios; Asociación Ondarezain; Cátedra unesco de la upna; Vicerrectorado de Investigación de la upna; la magistrada Esther Erice, la profesora titular de Derecho Internacional Público de la upna Alicia Chicharro, y los abogados especialistas en discapacidad Javier Miranda e Isabel Urzainqui.

El texto resultante de todo este proceso se presentó en la "Jornada de presentación del Anteproyecto de Ley Foral de Derechos Culturales", celebrada el 14 de febrero de 2018 en el Salón Pío Baroja (Edificio inap. Pamplona).
Tras una presentación general de la consejera de Cultura, Deporte y Juventud, Ana Herrera, intervinieron Javier Barcelona Llop y Roldán Jimeno Aranguren, que desglosaron los objetivos y contenido del Anteproyecto de Ley Foral. Asistieron a la Jornada cuarenta y seis personas pertenecientes a diversas entidades y organizaciones, públicas y privadas, del sector cultural.

El texto del Anteproyecto de Ley Foral de Derechos Culturales de Navarra fue informado favorablemente por la Comisión Foral de Régimen Local, de la que forman parte representantes de las entidades locales de Navarra. Asimismo, ha de hacerse constar que en la reunión de la Comisión Mixta Gobierno de Navarra-Iglesia Católica - órgano regido por el artículo 7.2 de la Ley Foral 14/2005, de 22 de noviembre, del Patrimonio Cultural de Navarra-, celebrada el 25 de abril de 2018, se analizó el texto del Anteproyecto de Ley Foral de Derechos Culturales de Navarra. Una vez finalizada la tramitación correspondiente, el Gobierno de Navarra aprobó el Proyecto de Ley Foral de Derechos Culturales de Navarra mediante Acuerdo de 19 de septiembre de 2018 y ordenó su remisión al Parlamento de Navarra. Finalmente, el Pleno del Parlamento de Navarra, en sesión celebrada el 11 de enero de 2019, aprobó la Ley Foral 1/2019, de 15 de enero,

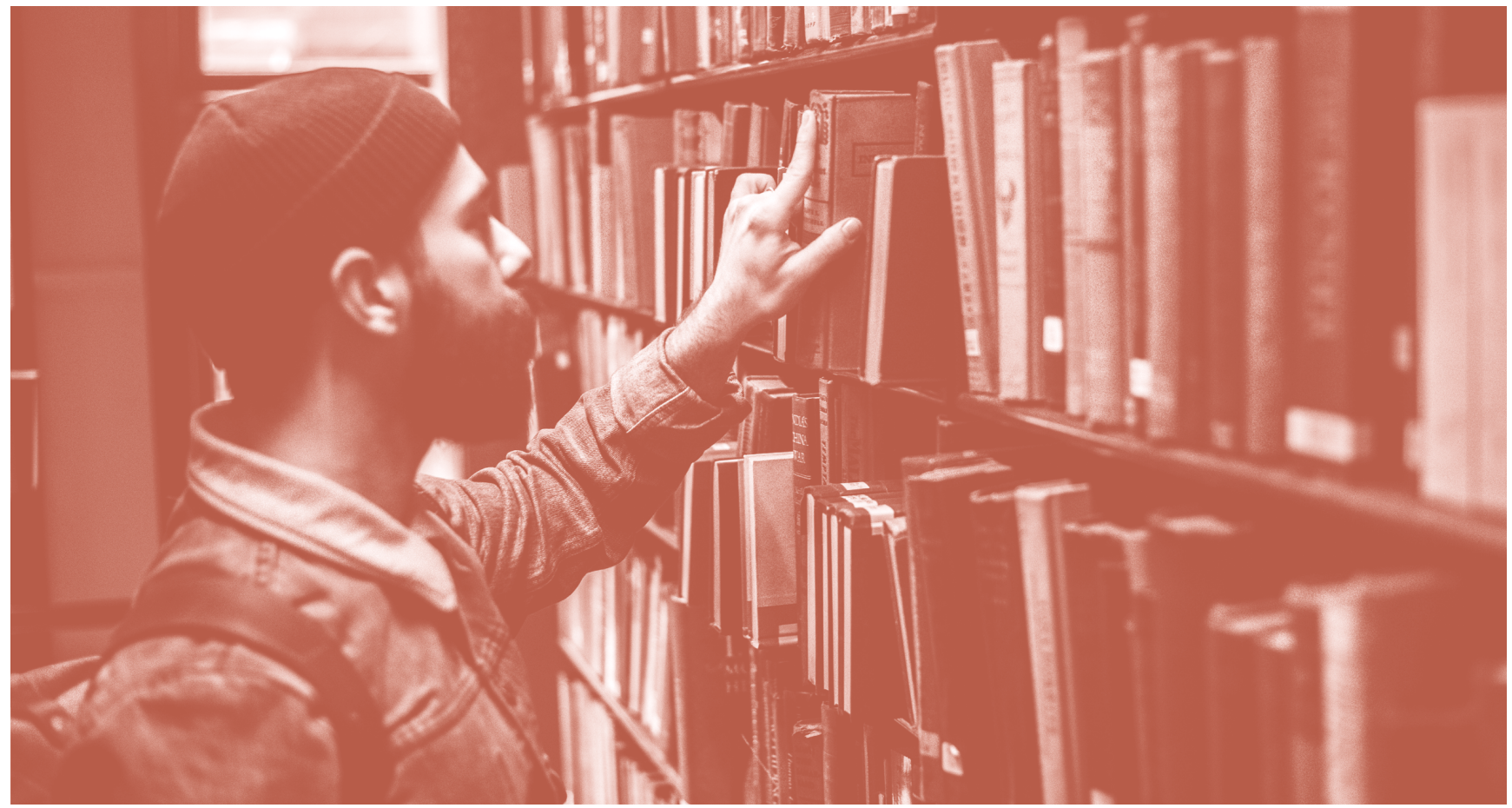


de Derechos Culturales de Navarra, que fue publicada en el Boletín Oficial de Navarra n. ${ }^{\circ}$ 17, de 25 de enero de 2019.

La Ley Foral se estructura en seis títulos, una disposición adicional, dos disposiciones transitorias, una disposición derogatoria y cinco disposiciones finales. El Título I contiene las Disposiciones Generales y recoge el objeto, los principios inspiradores y el ámbito de aplicación de la Ley Foral. Asimismo, enumera los derechos culturales y encomienda a los poderes públicos de la Comunidad Foral de Navarra que garanticen su pleno y libre ejercicio. El Título II regula el derecho de acceso a la cultura y a la participación en la vida cultural. Las administraciones públicas deben velar por el ejercicio de dichos derechos, promoviendo las condiciones y adoptando las medidas necesarias para que se realicen en régimen de igualdad efectiva, asegurando la inclusión de personas y grupos vulnerables, de personas con discapacidad y la igualdad entre hombres y mujeres.

En materia de acceso a la cultura se contempla, además del acceso físico a los centros culturales, museos, archivos, bibliotecas, teatros, auditorios, bienes integrantes del patrimonio cultural y, en general, cualesquiera equipamientos culturales, el acceso virtual a través de las tecnologías de la información y la mediación cultural. En cuanto al acceso virtual, la disposición transitoria segunda de la Ley Foral determina que

la Administración Foral de Navarra deberá tener abierto el Portal Digital de la Cultura de Navarra en el plazo máximo de tres años desde la aprobación de la presente ley foral. A estos efectos, el Gobierno deberá presentar un proyecto de diseño general de dicho portal en un plazo máximo de 6 meses a fin de que sea conocido y participado por el Parlamento de Navarra.

Se regula de manera específica el acceso a los bienes del patrimonio cultural de Navarra, determinando de manera concreta el régimen de la obligación de permitir la visita pública que en la Ley Foral 14/2005, de 22 de noviembre, del Patrimonio Cultural de Navarra aparece enunciada; el acceso y fomento del patrimonio inmaterial; el acceso al patrimonio documental, a los museos y colecciones museográficas permanentes y al libro y las bibliotecas.

En cuanto al ámbito cinematográfico y audiovisual, destaca la regulación de las funciones de la Filmoteca de Navarra, dependiente del Departamento competente en materia de cultura. También se contienen en el Título II disposiciones sobre las artes escénicas, la música, el ecosistema cultural y creativo y los equipamientos culturales. Finalmente, se reconoce el derecho de toda persona, de manera individual o colectiva, a la participación en la vida cultural y en los procesos importantes de adopción de decisiones relacionadas con las políticas públicas del ámbito cultural, en el marco de la normativa reguladora de la transparencia, acceso a la información pública y gobierno abierto, y sin perjuicio de lo dispuesto en otras normas que prevean o contemplen instrumentos de participación.

El Título III está dedicado a la creación artística y literaria y a la investigación científica. Por una parte, el Capítulo I se ocupa de la libertad de creación e investigación y, por otra, el Capítulo II contempla el fomento y difusión en dichos ámbitos por las administraciones públicas. El Título IV regula la responsabilidad de las administraciones públicas en materia de cultura, cuya actuación debe enmarcarse en la normativa reguladora de la transparencia de la actividad pública.

Se establecen los principios que han de guiar el acceso y uso de publicaciones propias de las administraciones e instituciones públicas de Navarra. Por otra parte, y con objeto de garantizar la profesionalización de las personas que trabajan en los sectores culturales, se establecen las actuaciones que deberá realizar el Departamento competente en materia de cultura. Por lo que respecta a la Administración de la Comunidad Foral, se atribuye al Departamento competente en materia de cultura el ejercicio de las competencias en lo relativo a la protección y el acrecentamiento del patrimonio cultural, al acceso a la cultura por la ciudadanía y al impulso y promoción de la creación y difusión artística, así como velar por la efectividad de los derechos reconocidos en la Ley Foral de derechos culturales y por el cumplimiento de la misma, sin perjuicio de las competencias que correspondan al Gobierno de Navarra y de la coordinación con el resto de departamentos de la Administración de la Comunidad Foral.

A tal efecto, se establecen las actuaciones, medidas y programas que el Departamento competente en materia de cultura deberá desarrollar para el cumplimiento de los fines y objetivos de la Ley Foral y para el efectivo reconocimiento y ejercicio de los derechos y principios inspiradores que contiene. En cuanto a los municipios, que de acuerdo con la legislación básica de régimen local ejercerán en todo caso como competencia propia la promoción de la cultura y equipamientos culturales, la Ley Foral les encomienda difundir y poner en valor su patrimonio cultural, sin perjuicio de la cooperación con el Departamento competente en la materia para su protección, acrecentamiento y transmisión. En particular, los municipios velarán por la difusión y promoción del patrimonio cultural inmaterial, procurando contextualizar histórica, cultural y territorialmente las diversas manifesta- 
ciones de las culturas tradicionales y populares de Navarra. Se enumeran los servicios culturales que, entre otros, promoverán los municipios en ejercicio de sus competencias por sí mismos o a través de entidades supramunicipales.

En el Título V se configura al Consejo Navarro de la Cultura y las Artes como el órgano consultivo y asesor de la Administración de la Comunidad Foral en materia de cultura, se enumeran sus funciones y se establece su composición, que deberá desarrollarse reglamentariamente al igual que su organización y funcionamiento.

El Consejo Navarro de la Cultura y las Artes viene a suceder al Consejo Navarro de Cultura, por lo que la disposición derogatoria única determina la derogación en particular del artículo 10 de la Ley Foral 14/2005, de 22 de noviembre, del Patrimonio Cultural de Navarra, que lo configuró legalmente; a su vez, en la disposición transitoria primera se establece que las referencias al Consejo Navarro de Cultura contenidas en el ordenamiento jurídico se entenderán realizadas al Consejo Navarro de la Cultura y de las Artes y que a la entrada en vigor de la Ley Foral el Consejo Navarro de la Cultura y de las Artes estará compuesto por los actuales miembros del Consejo Navarro de Cultura.

Una vez finalizado el mandato de los actuales miembros, conforme a lo establecido por la normativa vigente reguladora de la composición, organización y funcionamiento del Consejo Navarro de Cultura, se procederá a la renovación de la composición del Consejo Navarro de la Cultura y de las Artes de acuerdo con lo dispuesto en la Ley Foral.

El Título VI, dedicado a las disposiciones financieras y tributarias, contempla la financiación pública de la cultura, el establecimiento de subvenciones y ayudas por el Departamento competente en materia de cultura, la difusión del mecenazgo cultural y la creación, en su caso en colaboración con otros departamentos de la Administración de la Comunidad Foral u otras entidades, de fondos a los emprendimientos culturales y acceso al crédito. Por su parte, la Ley Foral se remite a la legislación foral tributaria en cuanto a los beneficios fiscales aplicables en materia de derechos culturales y menciona expresamente los relativos al mecenazgo cultural, al patrocinio y a las producciones cinematográficas y series audiovisuales. Por lo que respecta a la normativa fiscal de la Comunidad Foral, la disposición final tercera establece que

se adaptará a las propuestas y recomendaciones que en materia de fiscalidad y de compatibilidad de la percepción de prestaciones públicas con ingresos por derechos de propiedad intelectual y por actividades creativas, se incluyen en el informe de la Subcomisión para la elaboración de un Estatuto del Artista, aprobado en el mes de junio de 2018 en el Congreso de los Diputados.

En la disposición adicional única se establece que el departamento competente en materia de cultura deberá aprobar, en el plazo de un año a contar desde la entrada en vigor de esta Ley Foral, cartas de servicios en las que se detallarán las prestaciones en sus ámbitos de competencia. La disposición derogatoria única deroga cuantas disposiciones de igual o inferior rango se opongan a lo establecido en esta Ley Foral y, expresamente, el citado artículo 10 de la Ley Foral 14/2005, de 22 de noviembre, del Patrimonio Cultural de Navarra, y los apartados b) y c) de su artículo 28 una vez hayan entrado en vigor, de conformidad con el segundo párrafo de la disposición final quinta de esta Ley Foral, los apartados 2, 3, 4, 5 y 6 del artículo 10 .

\section{Notas}

(1) Puede consultarse en: http://red.pucp.edu. pe/ridei/files/2012/09/120919.pdf [fecha de consulta: 7/11/2019].

\section{Bibliografía}

BOLETÍN OFICIAL DE NAVARRA (2019): Ley Foral 1/2019, de 15 de enero, de Derechos Culturales de Navarra, Gobierno de Navarra n ${ }^{\circ}$ 17, fecha de consulta: 02/10/2019, http://www.navarra.es/home_es/Actualidad/BON/Boletines/2019/17/Anuncio-0/

FERNÁNDEZ PRADO, E. (1991): La política cultural, qué es y para qué sirve, Madrid, Trea.

MANGAS MARTÍN, A. (1998): Tratado de la Unión Europea, Tratado constitutivos de las Comunidades Europeas y otros actos básicos de Derecho Comunitario, Madrid, Tecnos.

PORTAL DE GOBIERNO ABIERTO DE NAVARRA (2019): Proyecto de Ley de Derechos Culturales de Navarra, fecha de consulta: 02/10/2019, https://gobiernoabierto. navarra.es/es/gobernanza/proyectos-de-ley-foral/proyecto-ley-foral-derechos-culturales-navarra

SYMONIDES,J. (2010): Derechos culturales: una categoría descuidada de derechos humanos, fecha de consulta: 02/10/2019, http://red.pucp.edu.pe/ridei/files/2012/09/120919.pdf

UNESCO-MÉXICO. (1982): Conferencia mundial sobre políticas culturales. Informe final, México D. F. (México). 